\title{
Occurrence of guaiacyl/p-hydroxyphenyl lignin in Arabidopsis thaliana T87 cells
}

\author{
Masaomi Yamamura ${ }^{1}$, Shohei Wada ${ }^{1}$, Norikazu Sakakibara ${ }^{1, a}$, Tomoyuki Nakatsubo \\ Shiro Suzuki ${ }^{1,2}$, Takefumi Hattori ${ }^{1}$, Migiwa Takeda ${ }^{3}$, Nozomu Sakurai ${ }^{3}$, \\ Hideyuki Suzuki ${ }^{3}$, Daisuke Shibata ${ }^{3}$, Toshiaki Umezawa ${ }^{1,2, *}$ \\ ${ }^{1}$ Research Institute for Sustainable Humanosphere, Kyoto University, Uji, Kyoto 611-0011, Japan \\ ${ }^{2}$ Institute of Sustainability Science, Kyoto University, Uji, Kyoto 611-0011, Japan; ${ }^{3}$ Kazusa DNA Research Institute, \\ Kisarazu, Chiba 292-0818, Japan \\ *E-mail: tumezawa@rish.kyoto-u.ac.jpＴel: +81-774-38-3625Ｆax: +81-774-38-3682
}

Received July 7, 2010; accepted August 23, 2010 (Edites by T. Aoki)

\begin{abstract}
Abstruct Arabidopsis thaliana is the most widely used model plant in the area of plant biosciences, and the cell line T87 is one of the most commonly used lines in Arabidopsis cell cultures. The characteristics of lignins in cultured cells often differ from those of lignins in intact plants. To date, nothing is known about the lignins of T87 cells. In this study, we characterized lignins of T87 cells using six analytical methods; phloroglucinol staining, thioacidolysis, nitrobenzene oxidation, alkaline hydrolysis, and Klason and acetyl bromide methods. These analyses clearly showed that lignins of T87 cells are composed of guaiacyl and p-hydroxyphenyl units, and are quite different from lignin found in the Arabidopsis inflorescence stem, which is composed of guaiacyl and syringyl units.
\end{abstract}

Key words: Arabidopsis thaliana, lignin, T87 cells.

In general, cultured plant cells are partly dedifferentiated, and secondary metabolism is often less active than in plant cells in intact plants. These characteristics are disadvantageous for studies on production of secondary metabolites in cultured cells. At the same time, however, these cells can be exploited for studies on metabolic regulation, especially upregulation. For example, a typical cultured cell system of Arabidopsis thaliana T87 cells (Axelos et al. 1992) were was used to study up-regulation of PAP1, a positive regulator of anthocyanin biosynthesis, where flavonoid biosynthesis was dramatically increased in transformed T87 cells compared with the control non-transformant cells (Daisuke Shibata et al. unpublished data). Thus, T87 cells have proved to be a useful system for studies on metabolic control by transcription factors.

In addition, the T87 cell line has various advantages for plant science research, because it can be transformed via Agrobacterium-mediated transformation (Ogawa et al. 2008a) and cryopreserved (Ogawa et al. 2008b), and it is readily available from the RIKEN Bioresource Center (http://www.brc.riken.go.jp/lab/epd/Eng/news/ 090202_t87.shtml).

Because of these advantages, T87 cells have been widely used for studies in diverse areas of plant science, including signal transduction and network analyses of gene expression (Sano et al. 2008), metabolomics (Kai et al. 2009), circadian rhythm (Nakamichi et al. 2003, 2004), and so on. Thus, it is feasible that T87 cells could be used to study mechanisms of cell wall formation, including lignification. However, the characteristics of lignins in cultured cells can differ from those of lignins in intact plants (Fukuda et al. 1988; Sarkanen and Hergert 1971). To date, nothing is known about the lignins of T87 cells, despite the fact that these cells are used extensively in studies on plant phenylpropanoid metabolism.

In this study, we characterized lignins in T87 cells using six lignin analytical methods, phloroglucinolhydrochloric acid staining, thioacidolysis, nitrobenzene oxidation, alkaline hydrolysis, and Klason and acetyl bromide methods. These analyses clearly showed that lignins of T87 cells are composed of guaiacyl (4hydroxy-3-methoxyphenyl) and $p$-hydroxyphenyl units. This differs from the lignins in inflorescence stems of Arabidopsis, which are composed of guaiacyl and syringyl (3,5-dimethoxy-4-hydroxyphenyl) units. 


\section{Materials and methods}

\section{T87 cells and plant materials}

T87 suspension-cultured cells were cultivated in $200 \mathrm{ml} \mathrm{mJPL} 3$ liquid medium according to Ogawa et al. (2008b) and harvested at 1-21 days after subculturing. The harvested T87 suspensioncultured cells were collected onto filter paper (Advantec Co., Ltd.) in a Buchner funnel. After removal of the medium, the collected cells were washed with $50 \mathrm{ml}$ MilliQ water, dewatered by suction filtration for $30 \mathrm{~s}$, weighed, and then stored in liquid nitrogen until use. In addition, T87 cells were maintained on mJPL3 agar medium and subcultured every 14 days. $A$. thaliana Columbia plants were cultivated under a 16-h light/8-h dark regime as reported previously (Nakatsubo et al. 2008a, 2008b).

\section{Sample preparation for lignin analyses}

Harvested T87 suspension-cultured cells and A. thaliana inflorescence stems (60 days old, $30 \mathrm{~cm}$ in height) were individually freeze-dried, powdered with a pestle and mortar, and extracted with $95 \%$ methanol at $60^{\circ} \mathrm{C}$ until the color of the powdered cells changed from green to pale yellow. Then, the powders were further extracted successively with hexane and distilled water and freeze dried. Hereafter, these samples are referred to as extracts-free powders in this paper. Then, the extracts-free powders were dried in an oven at $60^{\circ} \mathrm{C}$ to constant weight. The lignins in the dried extract-free powders were then analyzed by thioacidolysis, nitrobenzene oxidation, alkaline hydrolysis, and Klason and acetyl bromide methods.

\section{Chemicals}

$\left[\mathrm{OC}^{2} \mathrm{H}_{3}\right]$ Vanillin and $\left[\mathrm{OC}^{2} \mathrm{H}_{3} \times 2\right]$ syringaldehyde were synthesized previously (Sakakibara et al. 2007). All other reagents were obtained from Nacalai Tesque Co., Ltd. or Wako Pure Chemicals Co., Ltd., unless otherwise noted.

\section{Instrumentation}

Cells were observed under an Olympus BX51 microscope (Olympus Co., Ltd), and images were obtained using a digital camera (Olympus DP71, Olympus Co., Ltd.) connected to the microscope.

GC-MS was performed using a Shimadzu QP-5050A GCMS system (Shimadzu Co., Ltd.). The GC-MS conditions were as follows: Shimadzu Hicap CBP10-M25-0.25 column ( $25 \mathrm{~m} \times$ $0.22 \mathrm{~mm}$ ); carrier gas, helium; injection temperature, $230^{\circ} \mathrm{C}$; oven temperature, $40^{\circ} \mathrm{C}$ at $\mathrm{t}=0$ to $2 \mathrm{~min}$, then to $230^{\circ} \mathrm{C}$ at $40^{\circ} \mathrm{C}$ $\mathrm{min}^{-1}$; ionization, electron-impact mode $(70 \mathrm{eV})$.

Absorbance was measured with a UV-1600PC UV-visible spectrophotometer (Shimadzu Co., Ltd.).

\section{Phloroglucinol-hydrochloric acid staining}

The phloroglucinol-hydrochloric acid reaction was carried out according to the method of Herr (1992). A tiny amount of agarplate grown or liquid-cultured T87 cells was placed on a slide glass, and one drop of phloroglucinol-hydrochloric acid solution ( $1 \%$ phloroglucinol in $20 \%$ calcium chloride solution: hydrochloric acid $=25: 4, \mathrm{v} / \mathrm{v}$ ) was added. The cells were covered with a coverslip, which was then sealed in place with nail varnish to prevent damage to the optical system by hydrochloric acid. Staining of the cells was observed under a microscope.

\section{Thioacidolysis}

Thioacidolysis was carried out according to the method of Nakatsubo et al. (2008a). An aliquot of the thioacidolysis products thus obtained was dissolved in $8 \mu \mathrm{l}$ of $\mathrm{N}, \mathrm{O}$ bis(trimethylsilyl)acetamide (BSA), heated for $45 \mathrm{~min}$ at $60^{\circ} \mathrm{C}$, and $0.8 \mu \mathrm{l}$ of the BSA solution was injected into the GC-MS.

\section{Nitrobenzene oxidation}

Nitrobenzene oxidation was carried out using the microscale nitrobenzene oxidation method as reported previously (Yamamura et al. 2010). The internal standard (30 $\mu 1)$ consisted of a mixture $\left(10 \mathrm{mg} \mathrm{ml}^{-1}\right.$ each) of $\left[\mathrm{OC}^{2} \mathrm{H}_{3}\right]$ vanillin, $\left[\mathrm{OC}^{2} \mathrm{H}_{3} \times\right.$ 2] syringaldehide, and [ring- ${ }^{13} \mathrm{C}_{6}$ ] $-p$-hydroxybenzaldehyde. The formed hydroxybenzaldehydes and acids were quantified using the following calibration curves $\{p$-hydroxybenzaldehyde, $Y=$ $1.038 X-0.061,0.1-20 \mathrm{nmol}$ range; $p$-hydroxybenzoic acid, $Y=$ $5.704 X-2.834,0.1-15 \mathrm{nmol}$ range; vanillic acid, $Y=17.23 X-$ $3.817,0.1-15 \mathrm{nmol}$ range; syringic acid, $Y=5.635 X-0.715$, $0.1-15 \mathrm{nmol}$ range; where $X$ represents the amount of $p$ hydroxybenzaldehyde, $p$-hydroxybenzoic acid, vanillic acid, or syringic acid (nmol), respectively, and $Y$ represents the ion current ratio of $p$-hydroxybenzaldehyde or $p$-hydroxybenzoic acid/[ring $\left.-{ }^{13} \mathrm{C}_{6}\right]$ - $p$-hydroxybenzaldehyde $(1 \mathrm{nmol})$, vanillic acid/ $\left[\mathrm{OC}^{2} \mathrm{H}_{3}\right]$ vanillin $(1 \mathrm{nmol})$, or syringic acid $/\left[\mathrm{OC}^{2} \mathrm{H}_{3} \times 2\right]-$ syringaldehyde (1 nmol), respectively\}.

\section{Alkaline hydrolysis}

Alkaline hydrolysis was carried out by the method of Allison et al. (2009) with a slight modification. Twenty milligrams of the dried extract-free powder was placed into 2-ml screwcapped tube and $1.5 \mathrm{ml}$ oxygen-free $\mathrm{N}_{2}$-degassed $1 \mathrm{M} \mathrm{NaOH}$ was added. The tube was sealed under oxygen-free $\mathrm{N}_{2}$. Oxygen in the $\mathrm{N}_{2}$ gas was removed using an oxygen trap (Cat. No. 3,001-17,900, GL Sciences Inc.). The resulting suspension was mixed by vortexing and incubated with gentle shaking at $25^{\circ} \mathrm{C}$ for $24 \mathrm{~h}$ in the dark. After centrifugation $(16,100 \times g, 10 \mathrm{~min}$ at room temperature), the supernatant was transferred to a new 15-ml polypropylene tube, and $10 \mu 1$ o-coumaric acid $\left(1 \mathrm{nmol} \mu \mathrm{l}^{-1}\right)$ was added as an internal standard. The mixture was mixed by inverting, acidified to $\mathrm{pH} 2$ by the addition of $1.2 \mathrm{ml}$ of $2 \mathrm{~N} \mathrm{HCl}$, and then extracted three times with ethyl acetate (each $3 \mathrm{ml}$ ). The combined organic solutions were washed with a saturated aqueous $\mathrm{NaCl}$ solution and dried over anhydrous $\mathrm{Na}_{2} \mathrm{SO}_{4}$. Then, the organic solution obtained was evaporated off under high-vacuum and subjected to GC-MS analysis after trimethylsilylation $\{p$-coumaric acid, $Y=0.285 X-$ $0.001,0.1-15 \mathrm{nmol}$ range; ferulic acid, $Y=1.998 X-0.244,0.1-$ $15 \mathrm{nmol}$ range; where $X$ represents the amount of $p$-coumaric acid or ferulic acid (nmol), respectively, and $Y$ represents the ion current ratio of $p$-coumaric acid/o-coumaric acid $(5 \mathrm{nmol})$, or ferulic acid/o-coumaric acid $(1 \mathrm{nmol})$, respectively $\}$.

\section{Klason Lignin}

The Klason method was carried out exactly as described by Schwanninger and Hinterstoisser (2002). 


\section{Acetyl bromide method}

The standard analysis procedure for acetyl bromide lignin determination was carried out according to the method of Hatfield et al. (1999), which is a modification of the Dence method (Dence and Lin 1992a). The standard protocol was as follows. Briefly, powdered plant sample was placed into a Teflon-lined screw cap tube, then $5 \mathrm{ml}$ freshly prepared acetyl bromide regent $[25 \%(\mathrm{v} / \mathrm{v}) \mathrm{AcBr}$ in glacial acetic acid] was added, and tubes were capped immediately. The mixture was incubated at $50^{\circ} \mathrm{C}$ for $6 \mathrm{~h}$, and then transferred with the aid of acetic acid into a $100 \mathrm{ml}$ volumetric flask containing $10 \mathrm{ml} 2 \mathrm{M}$ $\mathrm{NaOH}$ and $20 \mathrm{ml}$ acetic acid. Hydroxylamine $(3.5 \mathrm{ml}, 0.5 \mathrm{M})$ was added, and the solution was diluted to $100 \mathrm{ml}$ with acetic acid. For each sample, the absorption spectrum between 200 and $400 \mathrm{~nm}$ and absorption at $280 \mathrm{~nm}$ was recorded with a UV1600PC UV-visible spectrophotometer.

\section{Results and discussion}

First, we stained T87 cells with phloroglucinolhydrochloric acid (Herr 1992) for histochemical analysis of lignified tissue. As shown in Figure 1A, B, both agarplate grown and liquid cultured T87 cells showed random staining. This result strongly suggested that the lignification occurred in some T87 cells. Some cells grown in the liquid medium showed coiled thickening, suggesting that they contained tracheary element structures (Figure 1C).

The dried extracts-free powders of T87 cells and $A$. thaliana inflorescence stems were subjected to thioacidolysis to confirm unequivocally the presence of lignin by identifying the phenylpropanoid monomers derived from the $\beta-O-4$ substructure (Nakatsubo et al. 2008a). Then, the dried extracts-free powder of T87 cells was analyzed by nitrobenzene oxidation to characterize the aromatic composition of lignins by determining the ratio of guaiacyl:syringyl:p-hydroxyphenyl groups (Yamamura et al. 2010). Lignin in the samples was quantified using the Klason and acetyl bromide methods (Dence 1992; Hatfield et al. 1999; Schwanninger and Hinterstoisser 2002).

As shown in Figure 2, GC-MS analysis of the thioacidolysis products showed the presence of phenyltrithioethylpropane compounds in the products. These compounds are derived specifically from $\beta-O-4$ substructures of lignin polymers, showing unequivocally that lignification occurs in $A$. thaliana T87 cells. Analysis of the aromatic substitution pattern of the $\beta-O$ 4 substructure-derived monomers revealed the presence of guaiacyl and $p$-hydroxyphenyl compounds, which indicated the presence of guiacyl and $p$-hydroxyphenyl lignins, respectively. In contrast, we detected mainly guaiacyl and syringyl compounds in the thioacidolysis products from the $A$. thaliana inflorescence stem, while only trace amounts of $p$-hydroxyphenyl compounds were detected by mass chromatographic analysis. Because of
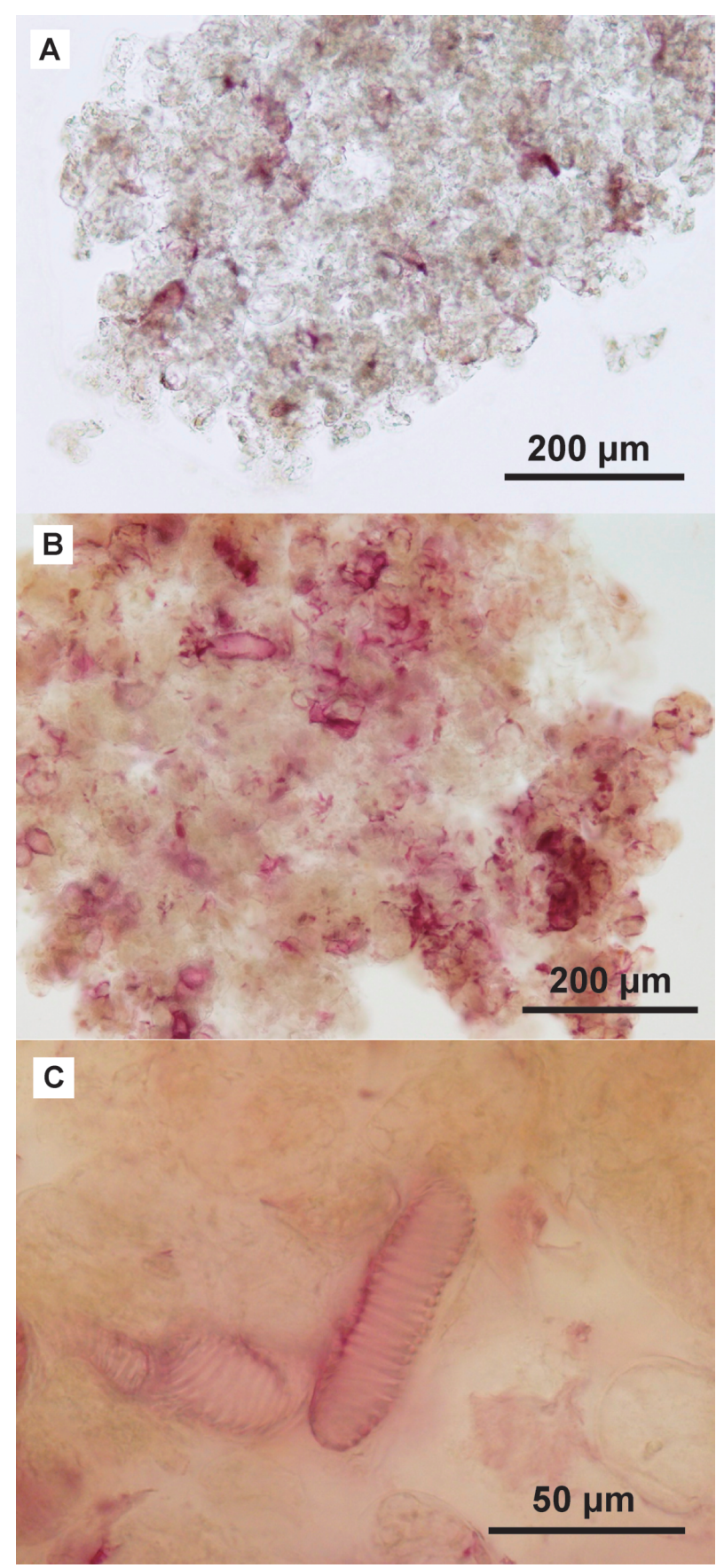

Figure 1. Phloroglucinol staining of T87 cells. (A) the agar-plate grown T87 cells (14 days). (B) the liquid cultured T87 cells (14 days). (C) the tracheary element structures observed in liquid cultured T87 cells.

their low abundance, the chromatographic peaks of $p$ hydroxyphenyl compounds on the total-ion chromatogram are not observed clearly in Figure 2.

The aromatic substitution pattern was further confirmed by nitrobenzene oxidation analysis, which reflects not only $\beta-O-4$ substructure but also other substructures. Our microscale nitrobenzene oxidation method using stable isotope-labeled internal standards (Yamamura et al. 2010) was successfully applied to T87 


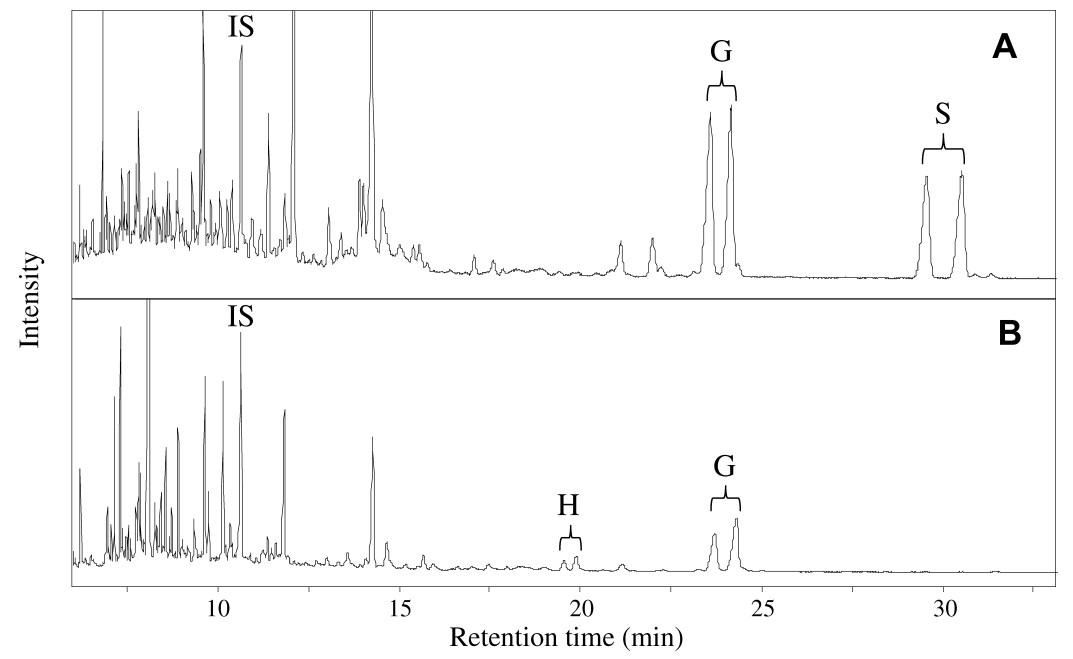

Figure 2. Total-ion chromatograms of thioacidolysis monomers derived from $\beta-O-4$ substructure. (A) A. thaliana infrorescence stem. (B) A. thaliana T87 cells (21 days). G, guaiacyl unit. S, syringyl unit. H, $p$-hydroxyphenyl unit. IS, internal standard (docosane).

cells. GC-MS analysis of the nitrobenzene oxidation products indicated the presence of vanillin and $p$ hydroxybenzaldehyde, but not syringaldehyde. The molar ratios of guaiacyl:syringyl:p-hydroxyphenyl units based on the amounts of the benzaldehydes were $6.3: 0$ : 1.0 in T87 cells and $52.0: 17.7: 1.0$ in A. thaliana plants (Table 1). These results clearly indicate that the T87 lignin is a guaiacyl and $p$-hydroxyphenyl lignin, but not a syringyl-type lignin (Figure 3).

In addition, the T87 lignin had a higher ratio of $p$ hydroxybenzoic acids/ $p$-hydroxybenzaldehydes than that from the $A$. thaliana inflorescence stem in the nitrobenzene oxidation analysis (Table 1). This result suggests that the side chains of T87 lignin contains higher amounts of carbonyl structures at benzyl positions than those of lignins in the inflorescence stem, because it was reported that the presence of carbonyl structures at benzyl positions lowers the yield of vanillin and generates an appreciable amount of vanillic acid (Chang and Allan 1971).

$p$-Hydroxyphenyl lignin is a typical component of lignins of gramineae plants or grasses (Higuchi et al. 1967a, 1967b; Lu and Ralph 1999; Ralph 2004, 2010). The $p$-hydroxyphenyl nuclei in grasses exist largely as $p$ coumarate esters, which are esterified to the terminal primary hydroxyl of the propyl side chain of syringyl units (Ralph 2010; Ralph et al. 1994, 2004). As well as $p$-coumarate, ferulic acid is involved in lignification during cell wall development in grasses. Ferulates in ferulate-polysaccharide esters are incorporated into lignin via the free-radical coupling processes that typically occur during lignification, producing strong lignin-polysaccharide crosslinks ( $\mathrm{Lu}$ and Ralph 1999). Ferulic acid and $p$-coumaric acid can be released from lignins of grasses by alkaline hydrolysis (Ralph et al. 2004). For example, $4,460 \mu \mathrm{g} \mathrm{g}^{-1}$ dry weight of ferulic

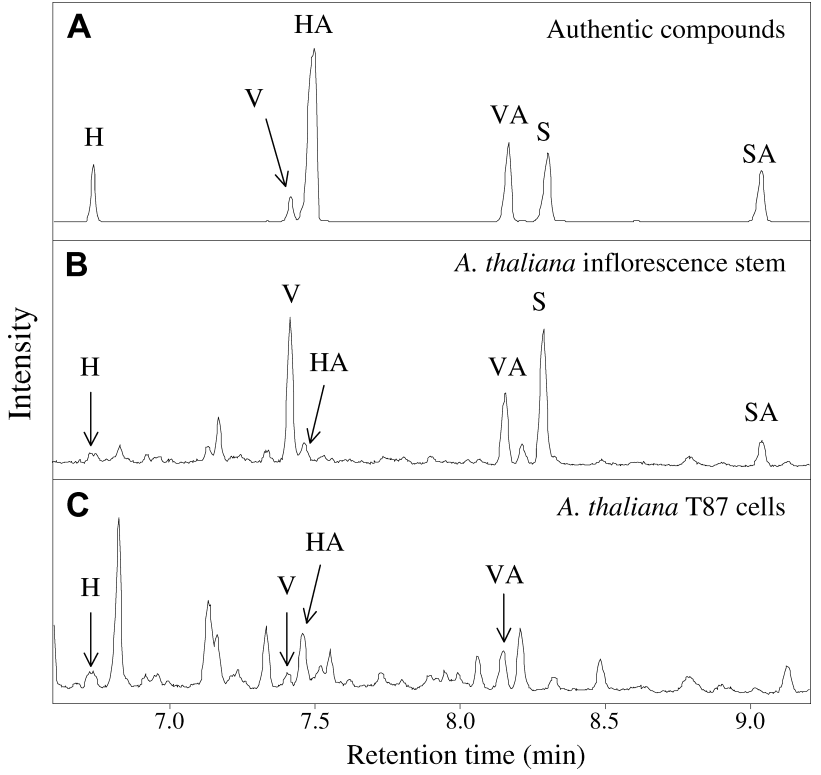

Figure 3. Total ion chromatograms of nitrobenzene oxidation products. (A) authentic compounds. (B) A. thaliana inflorescence stem. (C) A. thaliana $\mathrm{T} 87$ cells (21 days). V, vanillin. VA, vanillic acid. $\mathrm{S}$, syringaldehyde. SA, syringic acid. H, $p$-hydroxybenzaldehyde. HA, $p$ hydroxybenzonic acid.

acid and $14,070 \mu \mathrm{g} \mathrm{g}^{-1}$ dry weight of $p$-coumaric acid were obtained from Zea mays stalk (Marita et al. 2003), while only small amounts of ferulic acid and $p$-coumaric acid (27 and $32 \mu \mathrm{g} \mathrm{g}^{-1}$ dry weight) were released from the lignin of $A$. thaliana inflorescence stems (Derikvand et al. 2008). In this context, we determined the amounts of ferulic acid and $p$-coumaric acid in T87 suspensioncultured cells and A. thaliana inflorescence stems. GCMS analysis of alkaline hydrolysis products showed only small amounts of ferulic acid $\left(31.5 \mu \mathrm{gg}^{-1}\right.$ dry weight) and $p$-coumaric acid $\left(2.7 \mu \mathrm{g} \mathrm{g}^{-1}\right.$ dry weight) in T87 cells 
Table 1. Nitrobenzene oxidation and alkaline hydrolysis products

\begin{tabular}{lcc}
\hline \multicolumn{1}{c}{ Compounds } & $\begin{array}{c}\text { A. thaliana } \\
\text { T87 cells } \\
(21 \text { days })\end{array}$ & $\begin{array}{c}\text { A. thaliana } \\
\text { inflorescence } \\
\text { stem }\end{array}$ \\
\hline (A) Nitrobenzene oxidation & & \\
Vanillin (V) & $15.33 \pm 0.39$ & $52.23 \pm 1.05$ \\
Syringaldehyde (S) & n.d. & $21.34 \pm 0.54$ \\
$p$-Hydroxybenzaldehyde (H) & $1.97 \pm 0.05$ & $0.80 \pm 0.02$ \\
Vanillic acid (VA) & $3.19 \pm 0.06$ & $4.07 \pm 0.03$ \\
Syringic acid (SA) & n.d. & $2.26 \pm 0.02$ \\
$p$-Hydroxybenzoic acid (HA) & $0.61 \pm 0.01$ & $0.21 \pm 0.01$ \\
The molar ratio of V : S : H & $6.3: 0: 1.0$ & $52.0: 17.7: 1.0$ \\
(B) Alkaline hydrolysis & & \\
$p$-Coumaric acid & $2.7 \pm 0.1$ & $37.8 \pm 2.5$ \\
Ferulic acid & $31.5 \pm 1.0$ & $59.9 \pm 2.2$ \\
\hline
\end{tabular}

Data are mean values of replicate analyses $(n=3)$. (A) Amounts of nitrobenzene oxidation products These values are expressed in $\mathrm{mg} \mathrm{g}^{-1}$ of extract-free samples. (B) Amounts of products obtained by alkaline hydrolysis. These values are expressed in $\mu \mathrm{gg}^{-1}$ of extract-free samples. n.d. $=$ not detected.

(Table 1). The ferulic acid content in T87 cells is similar to the value obtained for $A$. thaliana inflorescence stems $\left(59.9 \mu \mathrm{gg}^{-1}\right.$ dry weight) in the present study (Table 1) and that reported in the literature for $A$. thaliana stems (27 $\mu \mathrm{gg}^{-1}$ dry weight) (Derikvand et al. 2008). On the other hand, the $p$-coumaric acid content in T87 cells is much lower than the value obtained for $A$. thaliana inflorescence stems $\left(37.8 \mu \mathrm{gg}^{-1}\right.$ dry weight) in the present study (Table 1) and that reported in the literature for $A$. thaliana stems (32 $\mu \mathrm{g} \mathrm{g}^{-1}$ dry weight) (Derikvand et al. 2008). In lignins of grasses, $p$-coumaric acid is esterified mainly to syringyl units (Lu and Ralph 1999). Hence, it seems rational to deduce that the lower content of $p$-coumaric acid in T87 cells is related to the absence of syringyl lignin. In any event, much higher amounts of these acids can be extracted from grasses (Harris and Trethewey 2010; Ralph 2010), indicating that the lignins in T87 cells differ from those of grasses in terms of their hydroxycinnamate esters content.

The lignin of T87 cells contained less $\mathrm{OCH}_{3}$ than that of the inflorescence stems. This is consistent with the results of lignin analysis of cultured cells of gymnosperm (Brunow et al. 1990, 1993; Fukuda et al. 1988; Lange et al. 1995) and angiosperm trees (Christiernin et al. 2005; Higuchi and Barnoud 1966; Higuchi et al. 1960; Wolter et al. 1974; Zaprometov et al. 1993). Normal developmental or constitutive lignins of gymnosperms and angiosperms are composed of guaiacyl and guaiacyl/ syringyl aromatic rings, respectively, while grass lignins contain significant amounts of $p$-hydroxyphenyl, as well as guaiacyl and syringyl units (Sarkanen and Hergert 1971). In contrast, Higuchi et al. (1960) found that a callus culture of the angiosperm tree, Paulownia tomentosa, yielded a lignin composed mainly of guaiacyl units with small amounts of syringyl units, indicating that its $\mathrm{OCH}_{3}$ content was much lower than that of its corresponding woody tissues, although $p$-hydroxyphenyl units were not detected. Higuchi et al. (1966), Wolter et al. (1974), and Christiernin et al. (2005) reported similar results for a number of cultured cell lines of angiosperm tree species including Populus tremuloides and Populus tremula $\times$ tremuloides. In addition, the lignin in Camellia sinensis cells cultured under heterotrophic conditions contained high levels of $p$-hydroxyphenyl lignin (Zaprometov et al. 1993). Similarly, lignins from suspension cultures of the gymnosperm trees, Pinus taeda and Picea abies had lower $\mathrm{OCH}_{3}$ contents than their corresponding woody tissues (Brunow et al 1990; Fukuda et al. 1988). This was ascribed to higher contents of $p$-hydroxyphenyl units (Brunow et al. 1993; Lange et al. 1995).

$p$-Hydroxyphenyl lignins are deposited at the initial stages of cell wall development, mainly into cell corners and compound middle lamellae both in gymnosperm and angiosperm trees (Fukushima and Terashima 1991; Terashima et al. 1998; Terashima and Fukushima 1988). The methoxyl contents of lignins increase at later developmental stages of cell wall formation in Pinus thumbergii (Terashima and Fukushima 1988). These observations suggest that the low methoxylation characteristics of lignin in T87 cells might be due to a developmentally regulated phenomenon, which was proposed by Higuchi and Barnoud as early as 1966 (Higuchi and Barnoud 1966; Kärkönen and Koutaniemi 2010).

It has also been shown that in Japanese radish (Raphanus sativus var. hortensis), p-hydroxyphenyl lignin formed in response to fungal infection (Asada and Matsumoto 1969). In addition, pumpkin (Cucurbita moschata) produced mainly $p$-hydroxyphenyl lignin in response to fungal infection, while sweet potato (Ipomoea batatas) and cucumber (Cucumis sativus) produced $p$-hydroxyphenyl and guaiacyl lignins (Uritani 2001; Uritani et al. 1975). Chinese cabbage (Brassica rapa ssp. pekinensis) also accumulated a lignin composed of more guaiacyl and $p$-hydroxyphenyl units when infected by a soft rot fungus, Erwinia carotovora subsp. carotovora (Zhang et al. 2007). On the other hand, wheat (Triticum aestivum), a monocotyledonous plant, produced syringyl-rich, but not $p$-hydroxyphenyl, lignin in response to a stem rust fungus (Puccinia graminis $\mathrm{f}$. sp. tritici) (Menden et al. 2007). However, it is particularly relevant to compare our data from T87 cells with those obtained from dicot plants, especially Japanese radish and Chinese cabbage, which like Arabidopsis, belong to the Brassicaceae family.

Cultured plant cells are subjected to hydrodynamic stress as a result of aeration and agitation of the cultures. Thus, stress reactions may have been induced in the T87 cells used in the present study. In fact, some pathogeninteraction related genes are upregulated in T87 cells 
compared with $A$. thaliana leaves, as indicated in the KEGG data base (Hideyuki Suzuki et al. unpublished data; Tokimatsu et al. 2005). Taken together, although it is still unclear whether aeration and agitation induce expression of genes that are involved in the regulation of the cinnamate/monolignol pathway, which gives rise to lignin synthesis in T87 cells, it is possible that $p$ hydroxyphenyl lignin formation in T87 cells represents a stress response.

Having the qualitative data in hand, we measured lignin content of T87 cells. We used the acetyl bromide method to determine lignin content of T87 cells, because this method is convenient and requires small amounts of samples. First, we used the standard protocol (Dence and Lin 1992) to determine lignin content of T87 cells that were harvested at 21 days after subculturing, followed by successive extraction with hot methanol and hexane. However, the analytical values obtained fluctuated each time (data not shown), and therefore, we used another protocol optimized for herbaceous plants (Hatfield et al. 1999). However, fluctuations of the data were still observed (data not shown), and so we modified the method to extract dried T87 cells with distilled water after hot methanol and hexane extraction. This modified method yielded reproducible results. We examined the effects of various reaction conditions, including reaction temperature, perchloric acid concentration, and reaction period. We determined lignin content to be $9.52 \pm 0.19 \%$ when the reaction was conducted at $50^{\circ} \mathrm{C}$ for $6 \mathrm{~h}$ without perchloric acid. The lignin content was determined to be $17.10 \pm 0.08 \%$ when the reaction was conducted at $70^{\circ} \mathrm{C}$ for $6 \mathrm{~h}$ without perchloric acid.

We also determined lignin contents of T87 cells (21 days) by Klason method (Schwanninger and Hinterstoisser 2002). Klason (acid-insoluble) and acid-soluble lignins in the extracts-free powders of T87 cells were determined as $11.33 \pm 1.11 \%$ and $6.42 \pm 0.16 \%$, respectively, and thus the total lignin content that is the summation of Klason and acid-soluble lignins was calculated as $17.75 \pm 1.26 \%$. The values of the acid-insoluble and the total lignin coincided with the lignin contents determined by the acetyl bromide method with reaction temperatures of $50^{\circ} \mathrm{C}$ and $70^{\circ} \mathrm{C}$, respectively. However, Hatfield et al. (1999) reported that the acetyl bromide reaction conducted at $70^{\circ} \mathrm{C}$ caused undesirable degradation of xylan, giving higher lignin content, while this degradation did not occur at $50^{\circ} \mathrm{C}$. Therefore, we used the reaction temperature of $50^{\circ} \mathrm{C}$ for measurement of lignin contents of T87 cells during 21 days of culture (Figure 4).

The lignin contents (\% of dry weight) and growth curve of T87 suspension-cultured cells are shown in Figure 4A, while total lignin amounts of T87 cells in $200 \mathrm{ml}$ medium in one flask are shown in Figure 4B. As shown in Figure 4A, the lignin content decreased from

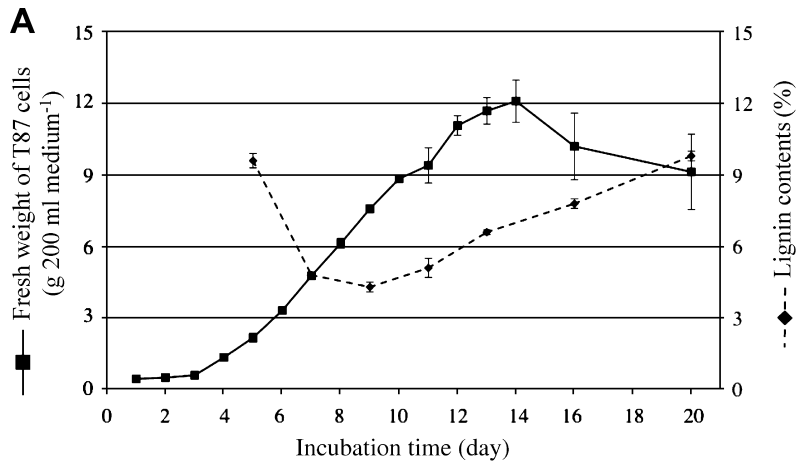

B

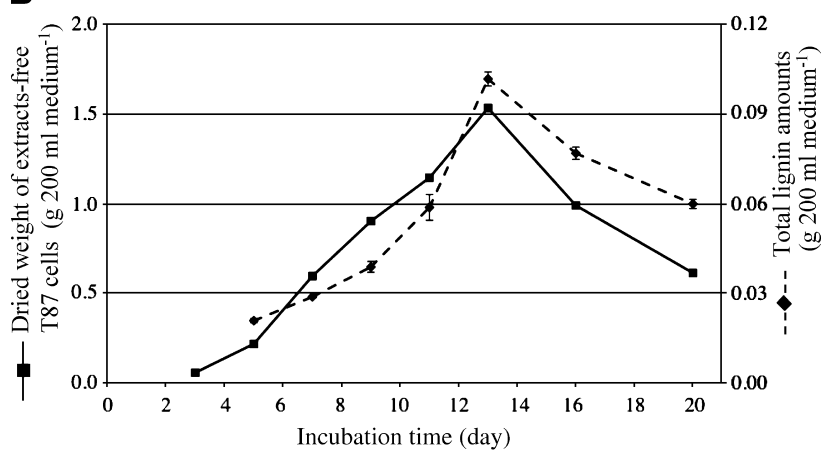

Figure 4. Time course of lignin contents of T87 suspension-cultured cells. (A) The lignin contents and growth curve of T87 suspensioncultured cells. Solid line shows growth curve of T87 suspensioncultured cells, and broken line shows their lignin contents expressed in $\%$ based on dry weight of extracts-free T87 cells. These data are mean values of replicate analyses $(n=3)$. (B) Total lignin amount in T87 cells of $200 \mathrm{ml}$ medium. Solid line shows weights of extracts-free dried T87 cells per $200 \mathrm{ml}$ medium. Broken line shows the total amount of lignin in the T87 cells per $200 \mathrm{ml}$ medium.

approximately 5 to 9 days after subculturing, and then increased. This pattern of lignin accumulation reflects rapid cell growth with less lignin biosynthesis at initial stages of rapid cell growth (up to 9 days after subculturing), and then activation of lignin biosynthesis at the latter stage of rapid cell growth (from 9 days after subculturing). The fresh weight of T87 suspensioncultured cells decreased from 14 days after subculturing, suggesting that some of the cultured cells may have died at this point and their cell contents were released into the medium.

In the present study, syringyl lignin was not detected in T87 cells (Table 1, Figures 2, 3). This is consistent with the fact that fiber cells were not observed in the cells (Figure 1), because fiber cell lignins are composed of guaiacyl and syringyl units. This suggests that T87 cells might be useful for identification of genes involved in fiber cell differentiation and genes that control syringyl lignin biosynthesis.

In this study, we showed for the first time that T87 cells contain lignin consisting of guaiacyl and $p$ hydroxyphenyl units. We did not detect syringyl lignin in T87 cells, which contrasts with the case in $A$. thaliana 
stems, in which the lignins are composed mainly of guaiacyl and syringyl lignins, with trace amounts of $p$ hydroxyphenyl lignin.

We successfully used the microscale nitrobenzene oxidation method (Yamamura et al. 2010) to analyze T87 cells and optimized the acetylbromide method for analyses of these cells. Together, the present study establishes a platform for microscale lignin analysis in T87 cells. This will be useful for studies on metabolic control of phenylpropanoid metabolism, including lignin biosynthesis.

\section{Acknowledgements}

We thank Ms. Midori Koda and Ms. Mika Gochomori for technical assistance. We also thank Dr. Keiji Takabe (Graduate School of Agriculture, Kyoto University) for the suggestion for microscopic analysis of T87 cells. This research was partly supported by Grants-in-Aid for Scientific Research from the Japan Society for the Promotion of Science (nos. 16380116, 18658069, and 20380102) and by grants from the New Energy and Industrial Technology Development Organization ("Development of Fundamental Technologies for Controlling the Process for Material Production of Plants" and "Research and development of genetic and metabolic information of energy producing plants for breeding programs"). A part of this study was conducted using the Forest Biomass Analytical System, Research Institute for Sustainable Humanosphere, Kyoto University.

\section{References}

Allison GG, Thain SC, Morris P, Morris C, Hawkins S, Hauck B, Barraclough T, Yates N, Shield I, Bridgwater AV, et al. (2009) Quantification of hydroxycinnamic acids and lignin in perennial forage and energy grasses by Fourier-transform infrared spectroscopy and partial least squares regression. Biores Technol 100: 1252-1261

Asada Y, Matsumoto I (1969) Formation of lignin-like substance in the root tissues of Japanese radish plant infected by downy mildew fungus. Ann Phytopath Soc Jpn 35: 160-167

Axelos M, Curie C, Mazzolini L, Bardet C, Lescure B (1992) A protocol for transient gene expression in Arabidopsis thaliana protoplasts isolated from cell suspension culture. Plant Physiol Biochem 30: 123-128

Brunow G, Ede RM, Simola LK, Lemmetyinen J (1990) Lignins released from Picea abies suspension cultures - true native spruce lignins? Phytochemistry 29: 2535-2538

Brunow G, Kilpeläinen I, Lapierre C, Lundquist K, Simola LK, Lemmetyinen J (1993) The chemical structure of extracellular lignin released by cultures of Picea abies. Phytochemistry 32: 845-850

Chang H-M, Allan GG (1971) Oxidation. In: Sarkanen KV, Ludwig CH (eds) Lignins. Wiley-Interscience, New York, pp 433-485

Christiernin M, Ohlsson AB, Berglund T, Henriksson G (2005) Lignin isolated from primary walls of hybrid aspen cell cultures indicates significant differences in lignin structure between primary and secondary cell wall. Plant Physiol Biochem 43: $777-785$
Dence CW, Lin SW (1992) In: Dence CW, Lin SW (eds) Methods in Lignin Chemistry. Springer-Verlag Berlin Heidelberg, pp 44-48

Derikvand MM, Sierra JB, Pollet B, Do C-T, Thévenin J, Buffard D, Jouanin L, Lapierre C (2008) Redirection of the phenylpropanoid pathway to feruloyl malate in Arabidopsis mutants deficient for cinnamoyl-CoA reductase 1. Planta 227: 943-956

Fukuda T, Mott R, Harada C (1988) Studies on Tissue Culture of Tree-Cambium XI. Characterization of lignin in suspensioncultured cells of loblolly pine. J Wood Sci (Mokuzai Gakkaishi) 34: 149-154 (in Japanese)

Fukushima K, Terashima N (1991) Heterogeneity in formation of lignin - XIV. Formation and structure of lignin in differentiating xylem of Ginkgo biloba. Holzforschung 45: 87-94

Harris PJ, Trethewey JAK (2010) The distribution of ester-linked ferulic acid in the cell walls of angiosperms. Phytochem Rev 9: 19-33

Hatfield RD, Grabber J, Ralph J, Brei K (1999) Using the Acetyl Bromide Assay To Determine Lignin Concentrations in Herbaceous Plants: Some Cautionary Notes. J Agric Food Chem 47: 628-632

Herr JM (1992) New Uses for Calcium Chloride Solution as a Mounting Medium. Biotech Histochem 67: 9-13

Higuchi T, Ishikawa H, Hasegawa M (1960) Chemical nature of lignin in cultured tissues of eastern white Pine and "Kiri" (Paulownia tomentosa) Tree. J Wood Sci (Mokuzai Gakkaishi) 6: 229-232 (in Japanese)

Higuchi T, Barnoud F (1966) Biogenesis of lignins of the tissues and plants cultured in vitro. J Wood Sci (Mokuzai Gakkaishi) 12: 36-43 (in Japanese)

Higuchi T, Ito Y, Kawamura I (1967a) p-Hydroxyphenylpropane component of grass lignin and role of tyrosine-ammonia lyase in its formation. Phytochemistry 6: 875-881

Higuchi T, Ito Y, Shimada M, Kawamura I (1967b) Chemical properties of milled wood lignin of grasses. Phytochemistry 6: $1551-1556$

Kai K, Hashidzume H, Yoshimura K, Suzuki H, Sakurai N, Shibata D, Ohta D (2009) Metabolomics for the characterization of cytochromes $\mathrm{P} 450$-dependent fatty acid hydroxylation reactions in Arabidopsis. Plant Biotechnol 26: 175-182

Kärkönen A, Koutaniemi S (2010) Lignin biosynthesis studies in plant tissue cultures. J Int Plant Biol 52: 176-185

Lam TBT, Iiyama K, Stone BA (1990) Distribution of free and combined phenolic acids in wheat internodes. Phytochemistry 29: 429-433

Lu F, Ralph J (1999) Detection and Determination of $p$ Coumaroylated Unit in Lignins. J Agric Food Chem 47: 1988-1992

Marita JM, Vermerris W, Ralph J, Hatfield RD (2003) Variations in the cell wall composition of Maize brown midrib mutants. $J$ Agric Food Chem 51: 1313-1321

Menden B, Kohlhoff M, Moerschbacher BM (2007) Wheat cells accumulate a syringyl-rich lignin during the hypersensitive resistance response. Phytochemistry 68: 513-520

Nakamichi N, Matushika A, Yamashino T, Mizuno T (2003) Cell autonomous circadian waves of the APRR1/TOC1 quintet in an established cell line of Arabidopsis thaliana. Plant Cell Physiol 44: 360-365

Nakamichi N, Ito S, Oyama T, Yamashino T, Kondo T, Mizuno T (2004) Characterization of Plant Circadian Rhythms by Employing Arabidopsis cells with bioluminescence reporters. 
Plant Cell Physiol 45: 57-67

Nakatsubo T, Kitamura Y, Sakakibara N, Mizutani M, Hattori T, Sakurai N, Shibata D, Suzuki S, Umezawa T (2008a) At5g54160 gene encodes Arabidopsis thaliana 5-hydroxyconiferaldehyde O-methyltransferase. J Wood Sci 54: 312-317

Nakatsubo T, Mizutani M, Suzuki S, Hattori T, Umezawa T (2008b) Characterization of Arabidopsis thaliana Pinoresinol Reductase, a new type of enzyme involved in lignan biosynthesis. J Biol Chem 283: 15550-15557

Ogawa Y, Dansako T, Yano K, Sakurai N, Suzuki H, Aoki K, Noji M, Saito K, Shibata D (2008a) Efficient and high-throughput vector construction and Agrobacterium-mediated transformation of Arabidopsis thaliana suspension-cultured cells for functional genomics. Plant Cell Physiol 49: 242-250

Ogawa Y, Suzuki H, Sakurai N, Aoki K, Saito K, Shibata D (2008b) Cryopreservation and metabolic profiling analysis of Arabidopsis T87 suspension-cultured cells. CryoLetters 29: 427-436

Ralph J (2010) Hydroxycinnamates in lignification. Phytochem Rev 9: 65-83

Ralph J, Hatfield RD, Quideau S, Helm RF, Grabber JH, Jung H-JG (1994) Pathway of $p$-coumaric acid incorporation into maize lignin as revealed by NMR. J Am Chem Soc 116: 9448-9456

Ralph J, Lundquist K, Brunow G, Lu F, Kim H, Schatz PF, Marita JM, Hatfield RD, Ralph SA, Christensen JH et al. (2004) Lignins: Natural polymers from oxidative coupling of 4hydroxyphenylpropanoids. Phytochem Rev 3: 29-60

Sakakibara N, Nakatsubo T, Suzuki S, Shibata D, Shimada M, Umezawa $T$ (2007) Metabolic analysis of the cinnamate/ monolignol pathway in Carthamus tinctorius seeds by a stableisotope-dilution method. Org Biomol Chem 5: 802-815

Sano R, Ogata Y, Suzuki H, Ogawa Y, Dansako T, Sakurai N, Okazaki K, Aoki K, Saito K, Shibata D (2008) Over-expression of transcription associated factor genes co-expressed with genes of the mevalonate pathway, upstream of isoprenoid biosynthesis, in Arabidopsis cultured cells. Plant Biotechnol 25: 583-587

Sarkanen KV, Hergert HL (1971) Classification and distribution. In: Sarkanen KV, Ludwig CH (eds) Lignins. Wiley-Interscience, New York, pp 43-94
Schwanninger M, Hinterstoisser B (2002) Klason Lignin: Modifications to Improve the Precision of the Standardized Determination. Holzforschung 56: 161-166

Terashima N, Fukushima K (1988) Heterogeneity in formation of lignin-XI: An autoradiographic study of the heterogeneous formation and structure of pine lignin. Wood Sci Technol 22: 259-270

Terashima N, Nakashima J, Takabe K (1998) Proposed structure for protolignin in plant cell walls. In: Lewis NG, Sarkanen $\mathrm{S}$ (eds) ACS Symposium Series 697, Lignin and lignana biosynthesis. American Chemical Society, Washington D.C., pp 180-193

Tokimatsu T, Sakurai N, Suzuki H, Ohta H, Nishitani K, Koyama T, Umezawa T, Misawa N, Saito K, Shibata D (2005) KappaView. A web-based analysis tool for integration of transcript and metabolite data on plant metabolic pathway maps. Plant Physiol 138: 1289-1300

Uritani I, Terashima N, Kojima M (1975) Lignin formation in sweet potato and cucumber caused by injury or blight. Abst. 20th Lignin Chemistry Symposium, Nagoya, pp 65-66

Uritani I (2001) In: Uritani I (ed) Biochemistry and molecular biology of plant stress: focusing on tropical starchy roots. Japan Scientific Societies Press, Tokyo, pp 81-85

Wolter KE, Harkin JM, Kirk TK (1974) Guaiacyl lignin associated with vessels in Aspen callus cultures. Physiol Plant 31: 140143

Yamamura M, Hattori T, Suzuki S, Shibata D, Umezawa T (2010) Microscale alkaline nitrobenzene oxidation method for highthroughput determination of lignin aromatic components. Plant Biotechnol 27: 305-310

Zaprometov MN, Zagoskina NV, Elkin VV (1993) Comparative study of lignins produced by the tea-plant and by tea-plant derived callus tissues. Phytochemistry 32: 709-711

Zhang S-H, Yang Q, Ma R-C (2007) Ervinia carotovora ssp. carotovora infection induced "defense lignin" accumulation and lignin biosynthetic gene expression in Chinese cabbage (Brassica rapa L. ssp. pekinensis). J Int Plant Biol 49: 9931002 